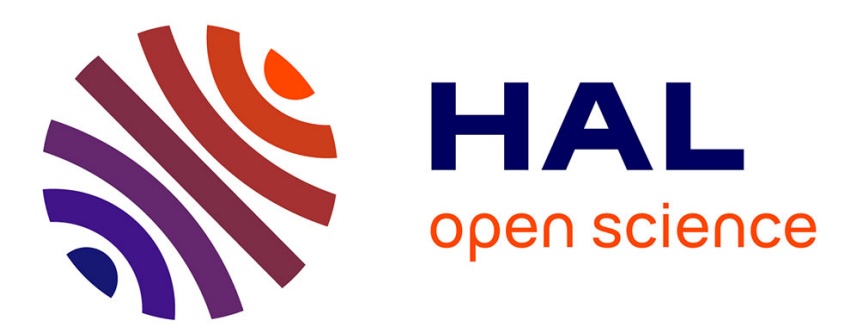

\title{
Inbreeding impact on litter size and survival in selected canine breeds
}

Grégoire Leroy, Florence Phocas, Benoit Hedan, Etienne Verrier, Xavier X Rognon

\section{> To cite this version:}

Grégoire Leroy, Florence Phocas, Benoit Hedan, Etienne Verrier, Xavier X Rognon. Inbreeding impact on litter size and survival in selected canine breeds. The Internet Journal of Veterinary Medicine, 2015, 203 (1), pp.74-78. 10.1016/j.tvjl.2014.11.008 . hal-01122782

HAL Id: hal-01122782

https://hal-univ-rennes1.archives-ouvertes.fr/hal-01122782

Submitted on 4 Mar 2015

HAL is a multi-disciplinary open access archive for the deposit and dissemination of scientific research documents, whether they are published or not. The documents may come from teaching and research institutions in France or abroad, or from public or private research centers.
L'archive ouverte pluridisciplinaire HAL, est destinée au dépôt et à la diffusion de documents scientifiques de niveau recherche, publiés ou non, émanant des établissements d'enseignement et de recherche français ou étrangers, des laboratoires publics ou privés. 
1 Inbreeding impact on litter size and survival in selected canine breeds

2

3

4

5

6

7 8 9

13

14

15

Grégoire Leroy ${ }^{\mathrm{a}, \mathrm{b}, *}$, Florence Phocas ${ }^{\mathrm{a}, \mathrm{b}}$, Benoit Hedan ${ }^{\mathrm{c}}$, Etienne Verrier ${ }^{\mathrm{a}, \mathrm{b}}$, Xavier Rognon ${ }^{\mathrm{a}, \mathrm{b}}$ a AgroParisTech, UMR 1313 Génétique Animale et Biologie Intégrative, F-75231 Paris, France ${ }^{\mathrm{b}}$ INRA, UMR 1313 Génétique Animale et Biologie Intégrative, F-78352 Jouy-en-Josas, France ${ }^{\mathrm{c}}$ CNRS/Université de Rennes, UMR 6061Institut de Génétique et Développement de Rennes, F35065 Rennes, France

* Corresponding author. Tel.: +33 144081746.

E-mail address: gregoire.leroy@agroparistech.fr (G. Leroy). 


\section{Highlights}

18 - In dogs, litter size and 2 year survival are traits with relatively low heritability level.

19 - A large part of within-breed inbreeding is related to assortative mating practice.

20 - Litter size is negatively affected by both litter and dam inbreeding.

21 - 2 year survival and longevity are negatively affected by inbreeding.

22 - Measures should therefore be taken by canine breed clubs to avoid mating of close

23 relatives.

24 
25

Page 3 of 25 


\section{Abstract}

27 Data obtained from the French Kennel Club and the Fichier National Canin were used to

28 estimate the effect of inbreeding on average litter size and survival in seven French breeds of

29 dog. Depending on the breed, litter sizes were 3.5-6.3 puppies and longevities were 7.7-12.2

30 years. Estimated heritabilities were $6.0-10.9 \%$ for litter size and $6.1-10.1 \%$ for survival at 2 years

31 of age. Regression coefficients indicated a negative effect of inbreeding on both individual

32 survival and litter size. Although the impact of baseline inbreeding within breeds appears to be

33 limited, the improper mating of close relatives will reduce biological fitness through significant

34 reduction of litter size and longevity.

35

36 Keywords: Canine; Inbreeding depression; Survival; Longevity; Litter size 

61 inbreeding depression.

\section{Introduction}

Inbreeding is a phenomenon that is difficult to avoid in domestic species because breeds constitute selected populations with limited sizes (Kristensen and Sorensen, 2005). In pet animals, mating between close relatives (e.g. between half- or full siblings) is still a common breeding practice (Leroy and Baumung, 2011). As an example, 24\% of French dog breeders have declared having practised such matings (Leroy et al., 2007) with the main purpose being to 'fix the qualities of a given reproducer'. Given the deleterious consequences of inbreeding on health through inbreeding depression and diffusion of inherited diseases within the breed (Bateson and Sargan, 2012), management of inbreeding should be a major concern for dog breeders.

Inbreeding depression is defined as the reduction of the mean phenotypic value shown by a given trait in relation to inbreeding (Falconer and Mackey, 1996). The phenomenon is well documented for several traits in livestock species (Leroy, 2014). In dogs, consequences of inbreeding on traits related to reproduction or occurrence of some specific diseases have been reported previously (Ubbink et al., 1992; van der Beek et al., 1999; Maki et al., 2001; Ólafsdóttir and Kristjánsson, 2008; Urfer, 2009).

Litter size and longevity constitute two interesting life history indicators because they are tightly linked to prenatal and postnatal survival. In dogs, there is strong variability of these two traits in relation to the large morphological differences existing amongst breeds. Longevity relating to body size or occurrence of various disorders has been studied in dogs (Egenvall et al., 2005; Greer et al., 2007; Kraus et al., 2013), but there is a lack of genetic characterisation of this trait. Similarly, litter size, which is genetically linked to female reproductive capacities and survival of the litter, also constitutes an interesting trait for the investigation of the impact of 
Based on the hypothesis that individual inbreeding may have a significant impact on dog

64 survival, the aim of this study was to provide a phenotypic and genetic characterisation of litter

65 size and longevity in seven breeds of dogs in France. We investigated inheritance and the impact

66 of inbreeding so as to provide practical recommendations for breeders.

67

68 Materials and methods

69 Source of population data

70 The French Kennel Club (Société Centrale Canine, SCC) has curated phenotypic and

71 genealogical information on dogs in France since 1975, using a database comprising all purebred

72 puppies registered at the age of 2 months. Dog owners are also supposed to indicate when their

73 dog dies (without giving the cause of death) to a national identification file (Fichier National

74 Canin, FNC). In practice, this information has been transmitted to and recorded in the FNC for

75 only $\sim 10 \%$ of dogs since 2005 . To study litter size, we considered litters born from 1990 to 2012

76 with at least three equivalent generations of known ancestors (Boichard et al., 1997). To assess

77 longevity, we considered individuals whose death had been registered in the years 2007 to 2012,

78 with at least three equivalent generations of known ancestors.

80 We chose seven breeds to cover a large range of morphology, use and demography,

81 namely the Bernese mountain dog (BMD), Basset hound (BSH), Cairn terrier (CAI), Epagneul

82 Breton (EPB), German shepherd dog (GSD), Leonberger (LEO) and West Highland white terrier 83 (WHW).

84

85 Statistical analysis 
An equivalent number of known generations $(E q G)$ and inbreeding coefficients $(F)$ were

computed with PEDIG software (Boichard, 2002), while estimates of variance components were

obtained using ASREML software (Gilmour et al., 2008). Analyses were independently

performed for each breed.

Litter size was defined as the number of puppies alive at registration, i.e. at the age of 2

months. Data were based on records ranging from 3468 (BSH) to 39,080 (GSD) litters born from

1543 (BSH) to 15,869 (GSD) bitches (Table 1; see Appendix: Supplementary Table 1). The trait

was analysed using a repeatability animal model and litter size as a trait of the dam (the 'animal' is therefore the dam of the litter):

$$
Y_{i r j m k}=\mu+P_{r}+B y_{j}+b_{1} F_{i}+b_{2} F_{i r}+b_{3} F_{m}+B r_{k+} P e_{i}+A_{i}+\mathcal{E}_{i r j l m k}
$$

where $Y_{\text {irjmk }}$ is the observed value of the $r$ th litter bred by sire $m$ and the dam $i$, raised by

100 the breeder $\mathrm{k}$, and $\mu$ is the overall mean. As environment factors, we included $P_{r}$ (the fixed effect

101 of the litter rank $r$ ), $B y_{j}$ (the fixed effect of birth year $j$ of the litter), $P e_{i}$ (the random permanent

102 environmental effect of the dam $i$ across all her litters) and $B r_{k}$ (the random effect of the breeder

$103 k$ of the litter). $b_{1}, b_{2}, b_{3}$ are the coefficients of regression of the phenotypic value $(Y)$ on the coefficients of inbreeding of the dam $\left(F_{i}\right)$, its $r$ th litter $\left(F_{i r}\right)$ and the sire of the $\mathrm{r}^{\text {th }}$ litter $\left(F_{m}\right)$, respectively. $A_{i}$ is the random genetic effect of dam $i$, and $\varepsilon_{\text {irjmk }}$ the random residual.

Longevity analyses were based on 1113 (BSH) to 15,059 (GSD) dogs whose death was

registered (Table 2). Models based on the trait itself did not lead to convergence during

110 bimodal distribution of longevity (Fig. 1), with a first mortality peak before 2 years in each 
111 breed, the trait was transformed into a binary variable describing juvenile survival; the value was

112 equal to 0 if the longevity was $<2$ years, and 1 otherwise. A linear model was written after a

113 probit transformation of the observed survival trait. The underlying normal dependent variable

$114 Y_{i j k l}$ was modelled as:

115

$$
Y_{i j k l}=\mu+S x_{j}+D y_{k}+b_{i} F_{i}+B R_{l}+A_{i}+\varepsilon_{i j k l}
$$

where $\mu$ is the mean, $S x_{j}$ is the fixed effect of $\operatorname{sex} j$ of animal $i, D y_{k}$ is the fixed effect of

119 death year $k, b_{i}$ is the regression coefficient for inbreeding of the individual $i, F_{i}$ is the inbreeding

120 coefficient of individual $i, B r_{l}$ is the random effect of breeder $l, A_{i}$ is the random genetic effect

121 for animal $i$ and $\mathcal{E}_{i j k l}$ is the random residual.

Heritabilities $\left(h^{2}\right)$ and other variance ratios were computed by dividing genetic variance

124 and variance components of all the other random effects by phenotypic variances for each

125 statistical model. To assess juvenile survival, heritability on the observed scale $\left(\mathrm{h}^{2}{ }_{01}\right)$ was

126 obtained by transforming heritability estimated on the underlying normal scale using the

127 following equation (Dempster and Lerner, 1950):

$$
h^{2}{ }_{01}=h^{2} \times z^{2} / p(1-p)
$$

where $p$ is the proportion of the population showing the trait (survival at 2 years) and $z$ is

131 the ordinate on the standard normal density function corresponding to the threshold $p$.

\section{Results}

\section{Demographic parameters}


Individual breeds had different population sizes, with the number of observations ranging from 1775 (longevity for LEO breed) to 39080 (litter size for GSD breed) (Table 1). Among the

137 breeds studied, BMD showed an increase in the number of litters produced over the 1990-2012

138 period (see Appendix: Supplementary Fig. 1). Since there are many hobby breeders, there was

139 only a small number of observations per female, per male or per breeder (see Appendix:

140 Supplementary Table 1); as an example, the average number of litters produced per male over

141 the 1990-2012 period ranged from 3.8 (LEO) to 9.9 (WHW). In each data set, the pedigree

142 knowledge was relatively good, with average $E q G$ ranging from 5.02 (longevity for BMD and

143 GSD) to 8.77 (litter size for EPB).

\section{Characterisation of traits}

The seven breeds showed large variations in the studied traits; average litter size ranged

147 from 3.5 (WHW) to 6.3 (LEO) puppies, with variations between years (Table 1; see Appendix:

148 Supplementary Fig. 1) and according to litter rank (Table 1; see Appendix: Supplementary Fig.

149 2). There was an increase in litter size until the second (BSH, EPB, GSD, LEO) or the third litter 150 (BMD, CAI, WHW), and then a decrease in subsequent ranks.

Mean longevity ranged from 7.7 (BMD) to 12.2 (CAI) years (Table 2), with three breeds

153 (CAI, EPB, WHW) showing a regular increase in longevity over the 6 year period of the study

154 (see Appendix: Supplementary Fig. 3). Male longevity was significantly lower $(P<0.001)$ than

155 female longevity for BMD and GSD, but higher for CAI and WHW (see Appendix:

156 Supplementary Fig. 4).

Inbreeding depression 
some contrasts across individuals; for example, the proportion of observations with inbreeding coefficient $F \geq 12.5 \%$ ranged from 2.4 (litter size for GSD) to $7.9 \%$ (litter size for CAI) (Tables

Fig. 2. In all breeds, litter size was significantly reduced $(P<0.05)$ for classes with more litter inbreeding. Litter size also decreased significantly $(P<0.05)$ for litters produced by dams of the BMD, CAI, GSD, LEO and WHW breeds with larger inbreeding coefficients. There were significant $(P<0.05)$ differences in longevity according to individual inbreeding levels for BMD, EPB, GSD, and LEO breeds (Fig. 2).

The regression coefficients for inbreeding were negative in all breeds for both litter size (litter and dam inbreeding effect) and 2 year survival (individual inbreeding effect). On average over all breeds, litter sizes were reduced by 0.026 per $\%$ of litter inbreeding and by 0.02 per $\%$ of dam inbreeding. In other words, we would expect, for litters with an inbreeding coefficient of $25 \%$ (equivalent to a mating between full siblings), a reduction of 0.65 puppies per litter on average in comparison with non-inbred litters. Females with this inbreeding coefficient could be expected to produce 0.5 puppies fewer per litter in comparison with non-inbred females. The coefficient of inbreeding for the sire had a significant effect on litter size only for EPB $(r=0.73$; $P=0.04)$ and WHW $(r=1.16 ; P=0.007)$.

\section{Variance components and quantitative genetic parameters}

181 and environment ratios (i.e. permanent environment variance divided by phenotypic variance)

182 for litter size ranged from $2.4(\mathrm{BSH})$ to $8.1 \%(\mathrm{EPB})$, and $0(\mathrm{BSH})$ to $9.81 \%(\mathrm{BMD})$, respectively

183 (see Appendix: Supplementary Table 2). 
No convergence was obtained for the estimation of variance components for survival for

LEO. Estimated values of heritability for survival for the different breeds (excluding LEO) were

22.4 (BSH) to $34.5 \%$ (GSD) on the underlying normal scale (see Appendix: Supplementary

Table 3). Corresponding heritability values on the $0-1$ bimodal scale were 5.9 (WHW) to $10.1 \%$

189 (GSD) (Table 3).

\section{Discussion}

The larger litter sizes and lower longevities for breeds of large size (BMD and LEO)

193 were in agreement with the results of previous studies (Borge et al., 2011; Kraus et al., 2013).

194 Distribution of mortality was similar to those found by Egenvall et al. (2005) and O'Neill et al.

195 (2013). The particularly low life expectancy of BMD (mean 7.7 years) may be a consequence of

196 the high prevalence of histiocytic sarcoma within this breed (Abadie et al., 2009).

The significantly lower life expectancy for male BMD and GSD are consistent with

199 previously published data (Bonnett et al., 2005; O'Neill et al., 2013). The significantly higher

200 male longevity in the two terrier breeds is unexpected. However, mortality risks related to sex

201 differ when considering different disorders; for example, Bonnett et al. (2005) showed that, in

202 general, females had up to two times greater risk of dying from tumours than males. Dog breeds

203 have large variations in disease prevalence and, therefore, variation between breeds in risk

204 related to sex is to be expected.

There were many (statistical) cells with few data because of low numbers of

207 performances per reproducer or per breeder (see Appendix A: Supplementary Table 1), which

208 led to difficulties in adjusting genetic models. It was possible to assess heritabilities for litter 
209 sizes with low to moderate heritabilities (6.0-10.9\%), of the same order to those estimated in

210 sheep, rabbits or pigs (Van Wyk et al., 2009; Nagy et al., 2012; Rodriguez et al., 2013).

211 However, a study on German shepherd and Labrador retriever guide dogs revealed much larger

212 heritabilities for litter size at 49 days (31 and 26\%, respectively) (Hare and Leighton, 2006),

213 which may result from better monitoring of those populations and a larger number of litters per

214 reproducer.

The structure of the data set did not allow identification of censured data (animals still

217 alive at the end of the study) and so it was not possible to perform direct survival analysis on

218 longevity data. Heritabilities estimated for 2 year survival were found in the same range (5.9-

$21910.1 \%$ according to breeds) as those reported for piglet and calf survival (4.2-19\%) (Gerra et al.,

220 2006; Rohe et al., 2009; Fuerst-Waltl and Sørensen, 2010).

Since litter size was measured at 2 months of age, i.e. after weaning, it was related to

223 female prolificacy, and embryo and early puppy survival. Therefore, it was not surprising to find

224 a negative impact of both litter and dam inbreeding on the trait. This result is in contrast with a

225 study on the Irish Wolfhound (Urfer, 2009), which found a limited impact of dam inbreeding on

226 litter size, although the data set was relatively small (822 litters). Inbreeding depression appeared

227 to be larger for breeds of larger body size, which could be linked to the larger litter size

228 estimated for those breeds. Supposing a similar impact of inbreeding on embryo and puppy

229 survival, the consequence of inbreeding on litter size could be expected to be higher for more

230 prolific breeds.

The scaled estimation of inbreeding depression (dividing the regression coefficient by the

233 mean of the phenotypic trait computed for the breed) was -0.27 to -0.65 for litter inbreeding and 
$234-0.13$ and -0.76 for dam inbreeding, with no notable difference according to breed size. This

235 result was within the range of values estimated in livestock for the number of offspring weaned

236 per litter, i.e. -0.69 (standard error 0.15 ) for litter inbreeding and -0.46 (standard error 0.17 ), for

237 dam inbreeding (Leroy 2014). This result is illustrated by the reduction in BMD of 0.8 puppies

238 between litters with inbreeding coefficients $<6.25 \%$, and litters with inbreeding coefficients $>$

$23912.5 \%$ (Fig. 2). In EPB and GSD, there was a difference of longevity of $>1$ year between dogs

240 with inbreeding coefficients $<6.25 \%$ and those with inbreeding coefficients $>12.5 \%$.

Although it was not possible to identify the causes of death, reduced longevity may be

243 linked to increased early mortality, early onset of senescence or increased rate of aging (Kraus et

244 al., 2013). However, given the importance of inherited disorders with a potential impact on dog

245 survival within dog breeds (Nicholas et al., 2011), it is probable that dogs with high inbreeding

246 have higher incidences of those disorders, which may significantly reduce their lifespan. As

247 emphasised by Leroy and Baumung (2010), high individual values of inbreeding coefficients (>

$2486.25 \%, 12.5$ or even $25 \%$ ) are most of the time caused by recent inbreeding, i.e. mating between

249 close relatives (cousins, half or full siblings, parent-offspring matings).

We consider that a large part of within-breed inbreeding is related to this breeding

252 practice. In 60 dog breeds studied, average coancestry at the breed scale was lower $(2.1 \%$ on

253 average) than inbreeding (3.5\% on average) (Leroy et al., 2013). The coefficient of coancestry

254 estimates the genetic similarity between two individuals and is equal to the coefficient of

255 inbreeding of a potential offspring of these two individuals. At the population scale, average

256 coancestry corresponds to baseline inbreeding, i.e. inbreeding because of the reduction of genetic

257 variability at the population scale. Therefore, within a breed under random mating conditions,

258 those two estimators should be similar, the difference here being explained by mating between 
259 close relatives. Given the low value of coancestry, this baseline inbreeding has a limited effect

260 on longevity. In contrast, at the individual level, Fig. 2 illustrates the deleterious impact of

261 mating between close-relatives on litter size and longevity. Therefore, measures should be taken

262 by breed clubs to avoid mating of close relatives (at least between parents-offspring, and half and

263 full siblings), for example, following the decision taken by the UK Kennel Club in $2009^{1}$.

265 Conclusions

266 The results presented in this study illustrate that inbreeding affects reproduction

267 parameters and survival at different stages of life in dogs. Improvement of these traits is

268 required, since the reduction of survival is generally related to health problems affecting animal

269 welfare. From a genetic point of view, survival of dogs could be improved by restricting mating

270 between close relatives, as well as through the implementation of efficient selection programmes

271 against widely spread inherited disorders. A third approach could be to consider a direct

272 selection on survival traits, given the heritabilities measured here. However there is a need to

273 improve the recording of phenotypes, in number and quality, before such a selection approach

274 could be implemented. Also, the development of molecular tools, allowing, among others,

275 genome-wide estimates of inbreeding, should improve our capacity to better understand and 276 manage inbreeding depression phenomenon.

278 Conflict of interest statement

279 None of the authors of this paper has a financial or personal relationship with other

280 people or organisations that could inappropriately influence or bias the content of the paper.

\section{Acknowledgements}

\footnotetext{
${ }^{1}$ See: http://www.thekennelclub.org.uk.
} 
The authors would like to thank the Société Centrale Canine for the data provided and

Wendy Brand-Williams for linguistic revision.

\section{References}

287

Abadie, J., Hedan, B., Cadieu, E., De Brito, C., Devauchelle, P., Bourgain, C., Parker, H.G., Vaysse, A., Margaritte-Jeannin, P., Galibert, F., et al., 2009. Epidemiology, pathology, and genetics of histiocytic sarcoma in the Bernese mountain dog breed. Journal of Heredity 100, S19-27.

Bateson, P., Sargan, D.R., 2012. Analysis of the canine genome and canine health: A commentary. The Veterinary Journal 194, 265-269.

Boichard, D., Maignel, L., Verrier, E., 1997. Value of using probabilities of gene origin to measure genetic variability in a population. Genetics Selection Evolution 29, 5-23.

Boichard, D., 2002. PEDIG: A fortran package for pedigree analysis suited for large populations. Proceedings of the 7th World Congress of Genetics Applied to Livestock Production, Montpellier, France, 19-23 August 2002, pp. 525-528.

Bonnett, B.N., Egenvall, A., Hedhammar, A., Olson, P., 2005. Mortality in over 350,000 insured Swedish dogs from 1995-2000: I. Breed-, gender-, age- and cause-specific rates. Acta Veterinaria Scandinavica 46, 105-120.

Borge, K.S., Tonnessen, R., Nodtvedt, A., Indrebø, A., 2011. Litter size at birth in purebred dogs - A retrospective study of 224 breeds. Theriogenology 75, 911-919.

Dempster, E.R., Lerner, I.M., 1950. Heritability of threshold characters. Genetics 35, 212.

Egenvall, A., Bonnett, B.N., Olson, P., Hedhammar, A., 2000. Gender, age and breed pattern of diagnoses for veterinary care in insured dogs in Sweden during 1996. Veterinary Record $146,551-557$.

Egenvall, A., Bonnett, B.N., Hedhammar, A., Olson, P., 2005. Mortality in over 350,000 insured Swedish dogs from 1995-2000: II. Breed-specific age and survival patterns and relative risk for causes of death. Acta Veterinaria Scandinavica 46, 121-136.

Falconer, D.S., Mackey, F.C. (Eds), 1996. Introduction to Quantitative Genetics, 4th Edn. Essex, $\mathrm{UK}, 464 \mathrm{pp}$.

Fuerst-Waltl, B., Sørensen, M.K., 2010. Genetic analysis of calf and heifer losses in Danish Holstein. Journal of Dairy Science 93, 5436-5442.

Gilmour, A.R., Gogel, B.J., Cullis, B.R., Thompson, R., 2008. ASReml User Guide Release 3, VSN International, Hemel Hempstead, UK. www.vsni.co.uk (accessed 9 November 2014). 
Greer, K.A., Canterberry, S.C., Murphy, K.E., 2007. Statistical analysis regarding the effects of height and weight on life span of the domestic dog. Research in Veterinary Science 82, 208-214.

Guerra, J.L.L., Franke, D.E., Blouin, D.C., 2006. Genetic parameters for calving rate and calf survival from linear, threshold, and logistic models in a multibreed beef cattle population. Journal of Animal Science 84, 3197-3203.

Hare, E., Leighton, E.A., 2006. Estimation of heritability of litter size in Labrador retrievers and German shepherd dogs. Journal of Veterinary Behavior 1, 62-66.

Kraus, C., Parvard, S., Promislow, D.E.L., 2013. The size-life span trade-off decomposed: Why large dogs die young. American Naturalist 181, 492-505.

Kristensen, T.N., Sorensen, A.C., 2005. Inbreeding - lessons from animal breeding, evolutionary biology and conservation genetics. Animal Science 80, 121-133.

Leroy, G., Verrier, E., Wisner-Bourgeois, C., Rognon, X., 2007. Breeding goals and breeding practices of French dog breeders: Results from a large survey. Revue de Médecine Vétérinaire 158, 496-503.

Leroy, G., Verrier, E., Meriaux, J.C., Rognon, X., 2009. Genetic diversity of dog breeds: Between-breed diversity, breed assignation and conservation approaches. Animal Genetics 40, 333-343.

Leroy, G., Baumung, R., 2011. Mating practices and the dissemination of genetic disorders in domestic animals, based on the example of dog breeding. Animal Genetics 42, 66-74.

Leroy, G., Rognon, X., 2012. Assessing the impact of breeding strategies on inherited disorders and genetic diversity in dogs. The Veterinary Journal 194, 343-348.

Leroy, G., 2014. Inbreeding depression in livestock species: Review and meta-analysis. Animal Genetics 189, 177-182

Mäki, K., Groen, A.F., Liinamo, A.E., Ojala, M., 2001. Population structure, inbreeding trend and their association with hip and elbow dysplasia in dogs. Animal Science 73, 217-228.

Nagy, I., Gorjanc, G., Curik, I., Farkas, J., Kiszlinger, H., Szendro, Z., 2012. The contribution of dominance and inbreeding depression in estimating variance components for litter size in Pannon white rabbits. Journal of Animal Breeding and Genetics, 1-9.

Nicholas, F.W., Crook, A., Sargan, D.R., 2011. Internet resources cataloguing inherited disorders in dogs. The Veterinary Journal 189, 132-135.

Ólafsdóttir, G.Á., Kristjánsson, T., 2008. Correlated pedigree and molecular estimates of inbreeding and their ability to detect inbreeding depression in the Icelandic sheepdog, a recently bottlenecked population of domestic dogs. Conservation Genetics 9, 1639-1641.

O’Neill, D.G., Church, D.B., McGreevy, P.D., Thomson, W., Brodbelt, D.C., 2013. Longevity and mortality of owned dogs in England. The Veterinary Journal 198, 638-643. 
381 Rodríguez, C., García Casco, J.M., Silió, L., 2013. Measuring effects of new and fast inbreeding on the litter size of Iberian pigs. Proceedings of the 8th International Symposium on the Mediterranean Pig, Ljubljana, Slovenia, 10-12 October 2013, Acta Argiculturae Slovenica Supplement 4. 21-23.

Roehe, R., Shrestha, N.P., Mekkawy, W., Baxter, E.M., Knap, P.W., Smurthwaite, K.M., Jarvis, S., Lawrence, A.B., Edwards, S.A., 2009. Genetic analyses of piglet survival and individual birth weight on first generation data of a selection experiment for piglet survival under outdoor conditions. Livestock Science 121, 173-181.

Ubbink, G.J., Knol, B.W., Bouw, J., 1992. The relationship between homozygosity and the occurrence of specific diseases in Bouvier Belge des Flandres dogs in The Netherlands. Veterinary Quarterly 14, 137-140.

Urfer, S.R., 2009. Inbreeding and fertility in Irish Wolfhounds in Sweden: 1976 to 2007. Acta Veterinaria Scandinavica 51, 21.

Van der Beek, S., Nielen, A.L., Schukken, Y.H., Brascamp, E.W., 1999. Evaluation of genetic, common-litter, and within-litter effects on preweaning mortality in a birth cohort of puppies. American Journal of Veterinary Research 60, 1106-1110.

Van Wyk, J.B., Fair, M.D., Cloete, S.W.P., 2009. Case study: The effect of inbreeding on the production and reproduction traits in the Elsenburg Dormer sheep stud. Livestock Science 120, 218-224. 
408 Fig. 1. Distribution of mortality over years according to breed. BMD, Bernese mountain dog;

409 BSH, Basset hound; CAI, Cairn terrier; EPB, Epagneul Breton; GSD, German shepherd dog;

410 LEO, Leonberger West; WHW, Highland white terrier.

413 Fig. 2. Average litter size and longevities according to inbreeding classes, considering for litter size the coefficient of inbreeding of the litter (a) or its dam (b), and for longevity the coefficient of the individual considered (c). BMD, Bernese mountain dog; BSH, Basset hound; CAI, Cairn terrier; EPB, Epagneul Breton; GSD, German shepherd dog; LEO , Leonberger West; WHW, Highland white terrier. ${ }^{\mathrm{NS}}$ non-significant; $* P<0.05$; ${ }^{* *} P<$ 0.01 ; *** $P<0.001$. 
419 Table 1 Main characteristics of litter size data according to breeds.

420

\begin{tabular}{|c|c|c|c|c|c|c|c|}
\hline \multirow[b]{2}{*}{ Breed $^{\text {a }}$} & \multirow[b]{2}{*}{$\begin{array}{l}\text { Number } \\
\text { of litters }\end{array}$} & \multirow{2}{*}{$\begin{array}{l}\text { Litter size (mean } \pm \\
\text { standard deviation) }\end{array}$} & \multirow{2}{*}{$\begin{array}{l}\text { Litter rank (mean } \pm \\
\text { standard deviation) }\end{array}$} & \multicolumn{4}{|c|}{ Litter inbreeding } \\
\hline & & & & $\begin{array}{c}\text { Mean } F^{b} \\
(\%)\end{array}$ & $\begin{array}{c}<6.25 \\
(\%)\end{array}$ & $\begin{array}{c}6.25-12.5 \\
(\%)\end{array}$ & $\begin{array}{c}\geq 12.5 \\
(\%)\end{array}$ \\
\hline BMD & 7566 & $5.51 \pm 2.78$ & $2.5 \pm 1.72$ & 2.08 & 88.8 & 7.1 & 4.1 \\
\hline BSH & 3468 & $5.14 \pm 2.66$ & $2.21 \pm 1.42$ & 3.92 & 76.6 & 16.8 & 6.5 \\
\hline CAI & 8846 & $3.89 \pm 1.77$ & $3.04 \pm 2.04$ & 3.25 & 82.6 & 9.5 & 7.9 \\
\hline EPB & 23,005 & $5.32 \pm 2.25$ & $2.53 \pm 1.96$ & 5.02 & 75.7 & 16.9 & 7.3 \\
\hline GSD & 39,080 & $5.1 \pm 2.44$ & $2.87 \pm 1.98$ & 2.42 & 88 & 8.3 & 3.6 \\
\hline LEO & 3246 & $6.33 \pm 3.08$ & $1.92 \pm 1.17$ & 3.21 & 85.9 & 10.5 & 3.7 \\
\hline WHW & 16,163 & $3.47 \pm 1.69$ & $2.87 \pm 1.92$ & 2.35 & 87.2 & 7.1 & 5.7 \\
\hline
\end{tabular}

421

$422{ }^{a}$ BMD, Bernese mountain dog; BSH, Basset hound; CAI, Cairn terrier; EPB, Epagneul Breton; GSD, German

423 shepherd dog; LEO, Leonberger West; WHW, Highland white terrier.

$424{ }^{\mathrm{b}}$ Inbreeding coefficient. 
425 Table 2 Main characteristics of longevity data according to breeds.

426

\begin{tabular}{|c|c|c|c|c|c|c|c|c|}
\hline \multirow[b]{2}{*}{ Breed $^{a}$} & \multirow[b]{2}{*}{$\begin{array}{l}\text { Number } \\
\text { of litters }\end{array}$} & \multirow[b]{2}{*}{$\begin{array}{l}\text { Longevity (mean } \pm \\
\text { standard deviation) }\end{array}$} & \multirow[b]{2}{*}{$\begin{array}{l}\text { Longevity } \\
\text { (median) }\end{array}$} & \multirow{2}{*}{$\begin{array}{c}2 \text { year } \\
\text { survivability } \\
(\%)\end{array}$} & \multicolumn{4}{|c|}{ Inbreeding } \\
\hline & & & & & $\begin{array}{c}\text { Mean } F^{b} \\
(\%)\end{array}$ & $\begin{array}{c}<6.25 \\
(\%)\end{array}$ & $\begin{array}{c}6.25-12.5 \\
(\%)\end{array}$ & $\begin{aligned} \geq & 12.5 \\
& (\%)\end{aligned}$ \\
\hline BMD & 2831 & $7.74 \pm 3.03$ & 8.15 & 93.7 & 1.59 & 91.7 & 5.1 & 3.2 \\
\hline BSH & 1113 & $9.33 \pm 3.67$ & 10.3 & 92 & 3.51 & 80.4 & 13.4 & 6.2 \\
\hline CAI & 2111 & $12.23 \pm 4.18$ & 13.42 & 95.4 & 3.2 & 82.3 & 10.2 & 7.4 \\
\hline EPB & 6286 & $11.34 \pm 4.28$ & 12.58 & 94.1 & 4.57 & 78.2 & 15.6 & 6.1 \\
\hline GSD & 15,056 & $9.16 \pm 3.72$ & 10.08 & 92.3 & 1.9 & 91 & 6.6 & 2.4 \\
\hline LEO & 1775 & $8.18 \pm 3.1$ & 8.75 & 94.5 & 3.26 & 84.6 & 11.5 & 3.9 \\
\hline WHW & 3559 & $11.89 \pm 3.92$ & 12.93 & 95.6 & 2.08 & 88.3 & 6.8 & 4.9 \\
\hline
\end{tabular}

427

$428{ }^{a}$ BMD, Bernese mountain dog; BSH, Basset hound; CAI, Cairn terrier; EPB, Epagneul Breton; GSD, German

429 shepherd dog; LEO, Leonberger West; WHW, Highland white terrier.

$430 \quad{ }^{\mathrm{b}}$ Inbreeding coefficient. 
431 Table 3 Heritabilities and estimates of inbreeding depression on litter size and 2 year survival. 432

\begin{tabular}{|c|c|c|c|c|c|c|}
\hline \multirow{3}{*}{ Breed $^{\mathrm{a}}$} & \multicolumn{4}{|c|}{ Litter size } & \multicolumn{2}{|r|}{2 year survival } \\
\hline & \multirow{2}{*}{$h^{2}$} & \multicolumn{3}{|c|}{ Inbreeding regression coefficient } & \multirow{2}{*}{$h^{2}{ }_{0 I}$} & \multirow{2}{*}{ Inbreeding regression coefficient } \\
\hline & & Litter & Dam & Sire & & \\
\hline BMD & 0.109 & $-3.06 * *$ & $-4.18 * *$ & $-1.89^{\mathrm{NS}}$ & 0.061 & $-2.04^{\mathrm{NS}}$ \\
\hline BSH & 0.06 & $-1.36^{\mathrm{NS}}$ & $-0.67^{\mathrm{NS}}$ & $0.02^{\mathrm{NS}}$ & 0.067 & $-0.98^{\mathrm{NS}}$ \\
\hline CAI & 0.098 & $-2.20 * * *$ & $-1.18 *$ & $0.14^{\mathrm{NS}}$ & 0.064 & $-1.57^{\mathrm{NS}}$ \\
\hline ЕРB & 0.1 & $-2.94 * * *$ & $-0.9^{\mathrm{NS}}$ & $0.73 *$ & 0.063 & $-2.70 * * *$ \\
\hline GSD & 0.091 & $-3.30 * * *$ & $-2.19 * * *$ & $0.90^{\mathrm{NS}}$ & 0.101 & $-2.80 * * *$ \\
\hline LEO & 0.882 & $-3.80 *$ & $-3.81^{\mathrm{NS}}$ & $1.50^{\mathrm{NS}}$ & - & - \\
\hline WHW & 0.105 & $-1.32 * * *$ & $-1.35 * *$ & $1.16 *$ & 0.059 & $-1.1^{\mathrm{NS}}$ \\
\hline
\end{tabular}

433

$434{ }^{a}$ BMD, Bernese mountain dog; BSH, Basset hound; CAI, Cairn terrier; EPB, Epagneul Breton; GSD, German

435 shepherd dog; LEO, Leonberger West; WHW, Highland white terrier.

$436 h^{2}$, heritability; $h^{2}{ }_{01}$, heritability on the observed scale; ${ }^{\text {NS }}$ non-significant; $* P<0.05 ; * * P<0.01 ; * * * P<0.001$. 


\section{Appendix}

440 Supplementary Fig. 1. Changes in number of litters registered and average litter size over years

441 according to breed BMD, Bernese mountain dog; BSH, Basset hound; CAI, Cairn terrier; EPB,

442 Epagneul Breton; GSD, German shepherd dog; LEO, Leonberger West; WHW, Highland white 443 terrier.

445 Supplementary Fig. 2. Changes in average litter size according to litter rank. BMD, Bernese 446 mountain dog; BSH, Basset hound; CAI, Cairn terrier; EPB, Epagneul Breton; GSD, German 447 shepherd dog; LEO, Leonberger West; WHW, Highland white terrier.

449 Supplementary Fig. 3. Changes in longevity over years according to breed BMD, Bernese 450 mountain dog; BSH, Basset hound; CAI, Cairn terrier; EPB, Epagneul Breton; GSD, German 451 shepherd dog; LEO, Leonberger West; WHW, Highland white terrier.

453 Supplementary Fig. 4. Average longevity according to the sex and breeds of individuals BMD, 454 Bernese mountain dog; BSH, Basset hound; CAI, Cairn terrier; EPB, Epagneul Breton; GSD, 455 German shepherd dog; LEO, Leonberger West; WHW, Highland white terrier. ${ }^{\text {NS }}$ non456 significant; * $P<0.05 ; * * P<0.01 ; * * * P<0.001$. 


\section{Supplementary Table 1}

458 Characteristics of data set analysed, considering litters born from 1990 to 2012 for litter size and 459 individuals whose death has been registered from 2007 to 2012 for longevity.

460

\begin{tabular}{|c|c|c|c|c|c|c|c|}
\hline Breed $^{\mathrm{a}}$ & Pedigree file & Trait & Number & Sires & Dams & Breeders & $E q G$ \\
\hline \multirow[t]{2}{*}{ BMD } & 55,434 & Litter size & 7565 & 1399 & 3138 & 917 & 5.59 \\
\hline & & Longevity & 2831 & 626 & 1171 & 608 & 5.02 \\
\hline \multirow[t]{2}{*}{ BSH } & 25,890 & Litter size & 3468 & 608 & 1543 & 606 & 6.34 \\
\hline & & Longevity & 1113 & 290 & 602 & 239 & 5.88 \\
\hline \multirow[t]{2}{*}{ CAI } & 43,399 & Litter size & 8846 & 1178 & 2855 & 1053 & 6.46 \\
\hline & & Longevity & 2111 & 547 & 1055 & 423 & 6.27 \\
\hline \multirow[t]{2}{*}{ ЕРB } & 190,395 & Litter size & 23,005 & 5402 & 10,711 & 5863 & 8.77 \\
\hline & & Longevity & 6286 & 2065 & 3476 & 1880 & 8.28 \\
\hline \multirow[t]{2}{*}{ GSD } & 419,447 & Litter size & 39,080 & 6966 & 15,869 & 5818 & 5.39 \\
\hline & & Longevity & 15,059 & 3447 & 6907 & 2524 & 5.02 \\
\hline \multirow[t]{2}{*}{ LEO } & 30,843 & Litter size & 3246 & 848 & 1730 & 846 & 6.68 \\
\hline & & Longevity & 1775 & 422 & 767 & 394 & 6.58 \\
\hline \multirow[t]{2}{*}{ WHW } & 70,464 & Litter size & 16,163 & 1629 & 5429 & 2205 & 5.81 \\
\hline & & Longevity & 3559 & 848 & 1927 & 845 & 5.50 \\
\hline
\end{tabular}

461

$462{ }^{a}$ BMD, Bernese mountain dog; BSH, Basset hound; CAI, Cairn terrier; EPB, Epagneul Breton; GSD, German

463 shepherd dog; LEO, Leonberger West; WHW, Highland white terrier.

$464 E q G$, equivalent number of known generations. 


\section{Supplementary Table 2}

466 Estimated variance ratios for models estimating litter size according to breeds.

467

\begin{tabular}{lcccc}
\hline Breed $^{\text {a }}$ & $h^{2} \pm$ standard deviation & $R V_{B R} \pm$ standard deviation & $R V_{P e} \pm$ standard deviation & $R V_{E} \pm$ standard deviation \\
\hline BMD & $0.109 \pm 0.203$ & $0.049 \pm 0.01$ & $0.098 \pm 0.019$ & $0.744 \pm 0.015$ \\
BSH & $0.06 \pm 0.014$ & $0.024 \pm 0.009$ & $0.0 \pm 0.0$ & $0.916 \pm 0.014$ \\
CAI & $0.098 \pm 0.018$ & $0.069 \pm 0.011$ & $0.085 \pm 0.016$ & $0.748 \pm 0.014$ \\
EPB & $0.1 \pm 0.01$ & $0.081 \pm 0.007$ & $0.059 \pm 0.01$ & $0.76 \pm 0.009$ \\
GSD & $0.091 \pm 0.008$ & $0.057 \pm 0.005$ & $0.088 \pm 0.008$ & $0.765 \pm 0.007$ \\
LEO & $0.088 \pm 0.027$ & $0.075 \pm 0.018$ & $0.092 \pm 0.029$ & $0.745 \pm 0.025$ \\
WHW & $0.105 \pm 0.013$ & $0.044 \pm 0.007$ & $0.059 \pm 0.011$ & $0.792 \pm 0.01$ \\
\hline
\end{tabular}

468

$469 h^{2}$, heritability ; $R V_{B R}$, breeder effect variance ratio ; $R V_{P e}$, permanent environmental variance ratio ; $R V_{E}$, residual

470 variance ratio.

471 a BMD, Bernese mountain dog; BSH, Basset hound; CAI, Cairn terrier; EPB, Epagneul Breton; GSD, German

472 shepherd dog; LEO, Leonberger West; WHW, Highland white terrier. 


\section{Supplementary Table 3}

474 Estimated variance ratios for models estimating 2 year survival according to breeds.

475

\begin{tabular}{lccc}
\hline Breed $^{\text {a }}$ & $h^{2} \pm$ standard deviation & $R V_{B R} \pm$ standard deviation & $R V_{E} \pm$ standard deviation \\
\hline BMD & $0.236 \pm 0.05$ & $0.124 \pm 0.046$ & $0.641 \pm 0.037$ \\
BSH & $0.224 \pm 0.074$ & $0.208 \pm 0.078$ & $0.568 \pm 0.051$ \\
CAI & $0.298 \pm 0.065$ & $0.054 \pm 0.057$ & $0.648 \pm 0.046$ \\
EPB & $0.253 \pm 0.031$ & $0.122 \pm 0.029$ & $0.625 \pm 0.024$ \\
GSD & $0.345 \pm 0.018$ & $0.056 \pm 0.015$ & $0.599 \pm 0.014$ \\
LEO & - & - & - \\
WHW & $0.289 \pm 0.048$ & $0.076 \pm 0.042$ & $0.635 \pm 0.035$ \\
\hline
\end{tabular}

476

$477 h^{2}$, heritability (additive variance); $R V_{B R}$, breeder effect variance ratio; $R V_{E}$, residual variance ratio.

$478{ }^{a}$ BMD, Bernese mountain dog; BSH, Basset hound; CAI, Cairn terrier; EPB, Epagneul Breton; GSD, German

479 shepherd dog; LEO, Leonberger West; WHW, Highland white terrier. 